\title{
Temperature Dependence and Mechanism of Chloride-Induced Aggregation of Silver Nanoparticles
}

Karen I. Peterson, * Megan E. Lipnick, Luis A. Mejia, and David P. Pullman*

Department of Chemistry and Biochemistry, San Diego State University, 5500 Campanile Drive, San Diego, California 92182-1030, United States

\section{Supporting Information}

Figure S1: TEM images of AgNP with $\mathrm{NaCl}$ added.

Figure S2: The time evolution of UV-Visible spectra of AgNP solutions after $\mathrm{NaCl}$ was added.

Figure S3: Volume \% DLS spectra of silver nanoparticle solutions; time evolution of the particle size when $\mathrm{NaCl}$ is added.

Figure S4: Comparison of aggregation rate of $\mathrm{AgNPs}$ in $\mathrm{NaCl} / \mathrm{Na}_{2} \mathrm{SO}_{4}$ solutions 

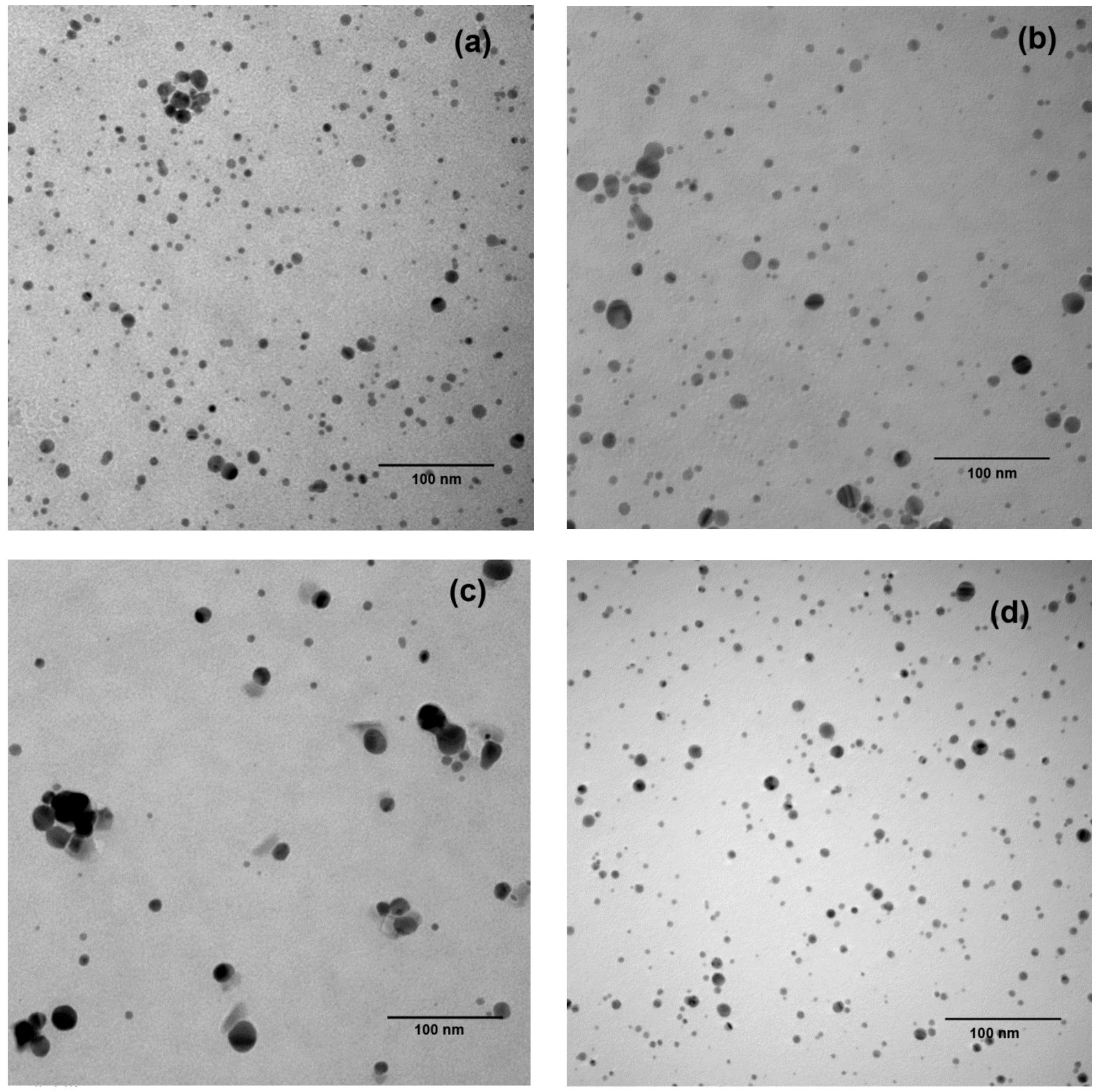

Figure S1. TEM images of $\mathrm{AgNP}$ with $\mathrm{NaCl}$ added. Each Formvar-coated copper grid was further coated by dropping $0.1 \% \mathrm{w} / \mathrm{v}$ aqueous polylysine on the grid, wicking away the excess moisture, and drying in air. Samples were prepared by dropping the appropriate AgNP solution on the grid, wicking away the excess moisture, and drying in air. Images of the following samples are shown: (a) $40 \mathrm{mM} \mathrm{NaCl}, 3$ minutes after $\mathrm{NaCl}$ was added; (b) $40 \mathrm{mM} \mathrm{NaCl}, 8$ minutes after $\mathrm{NaCl}$ was added; (c) $40 \mathrm{mM} \mathrm{NaCl}, 17$ minutes after $\mathrm{NaCl}$ was added; (d) $10 \mathrm{mM}$ $\mathrm{NaCl} ; 17$ minutes after $\mathrm{NaCl}$ was added. Note that in samples (a), (b), and (d), the color of the solutions was the same as when no $\mathrm{NaCl}$ was added, but the color had changed and some cloudiness was evident in sample (c). 

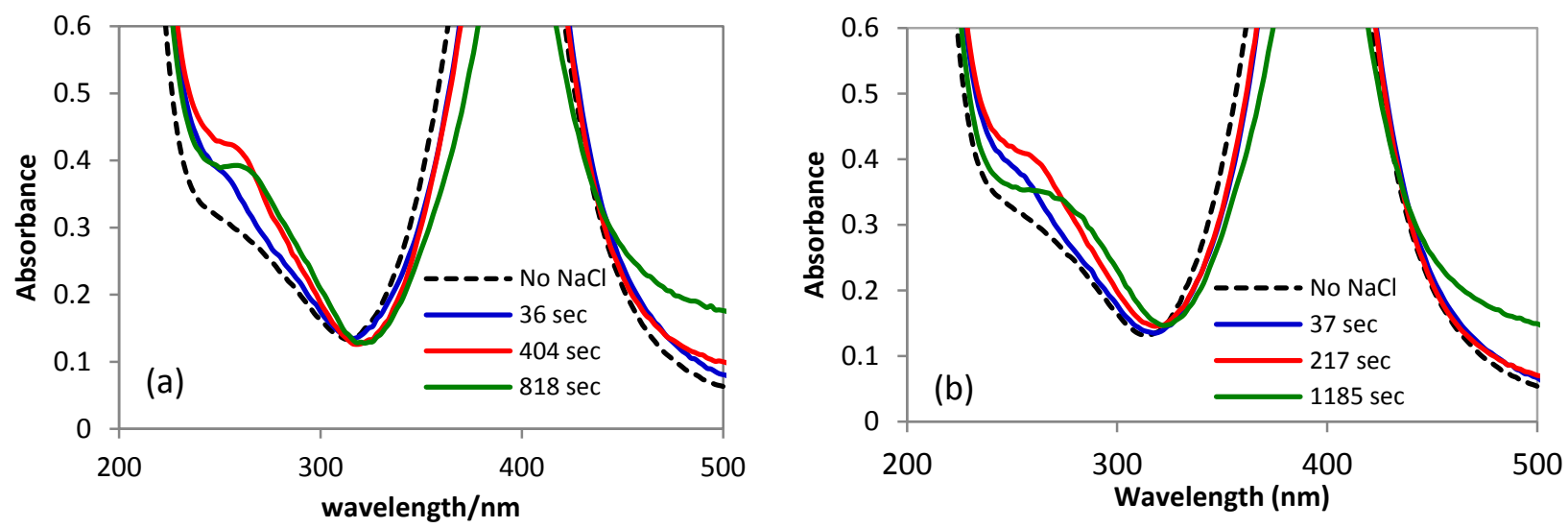

Figure S2. The time evolution of UV-Visible spectra of AgNP solutions after $\mathrm{NaCl}$ was added $([\mathrm{NaCl}]=40 \mathrm{mM})$. The expanded views are intended to highlight the absorbance of $\mathrm{AgCl}$ species in the wavelength region between 200 and $300 \mathrm{~nm}$. (a) $\mathrm{T}=15^{\circ} \mathrm{C}$. (b) $\mathrm{T}=25^{\circ} \mathrm{C}$.

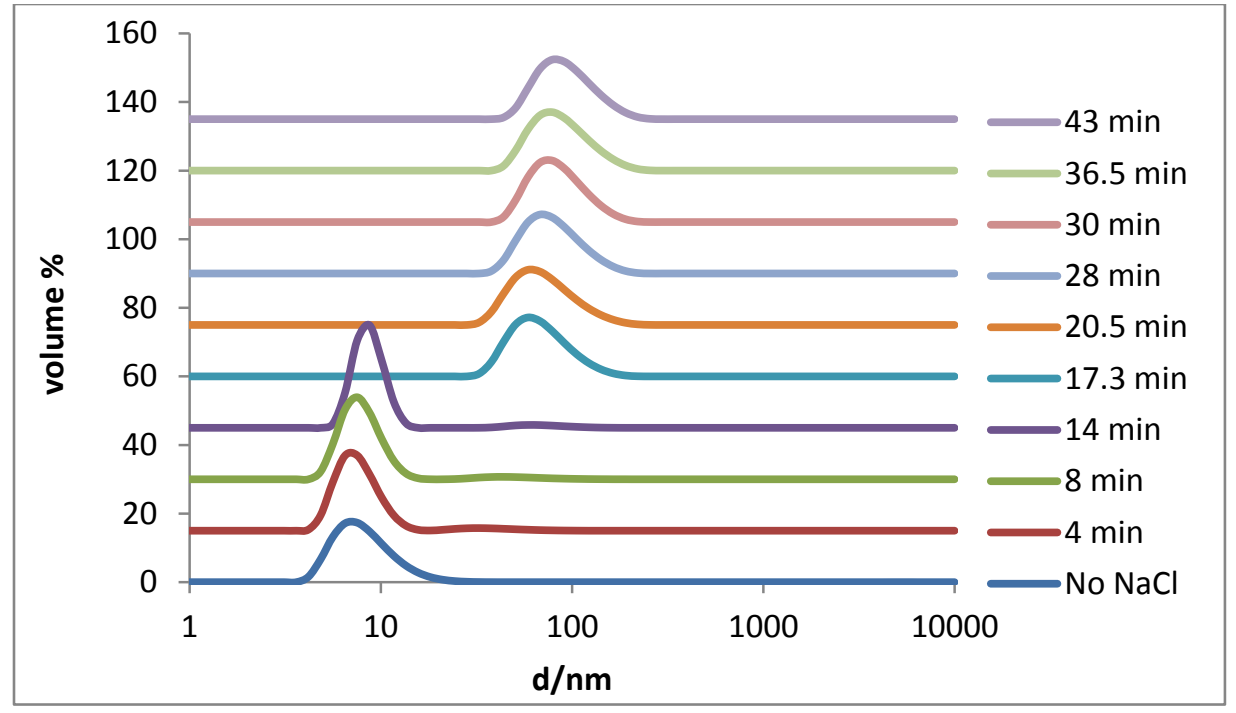

Figure S3. Volume \% DLS spectra of AgNP; $[\mathrm{Ag}]=0.30 \mathrm{mM}$; each spectrum is offset for clarity. $\mathrm{NaCl}$ was added after the first scan to obtain $7.4 \mathrm{mM} \mathrm{NaCl}$ in solution (final $[\mathrm{Ag}]=2.9$ $\mathrm{mM}$ ). Then spectra were taken every 3 to 8 minutes. Note the abrupt jump in particle size after $14 \mathrm{~min}$. 


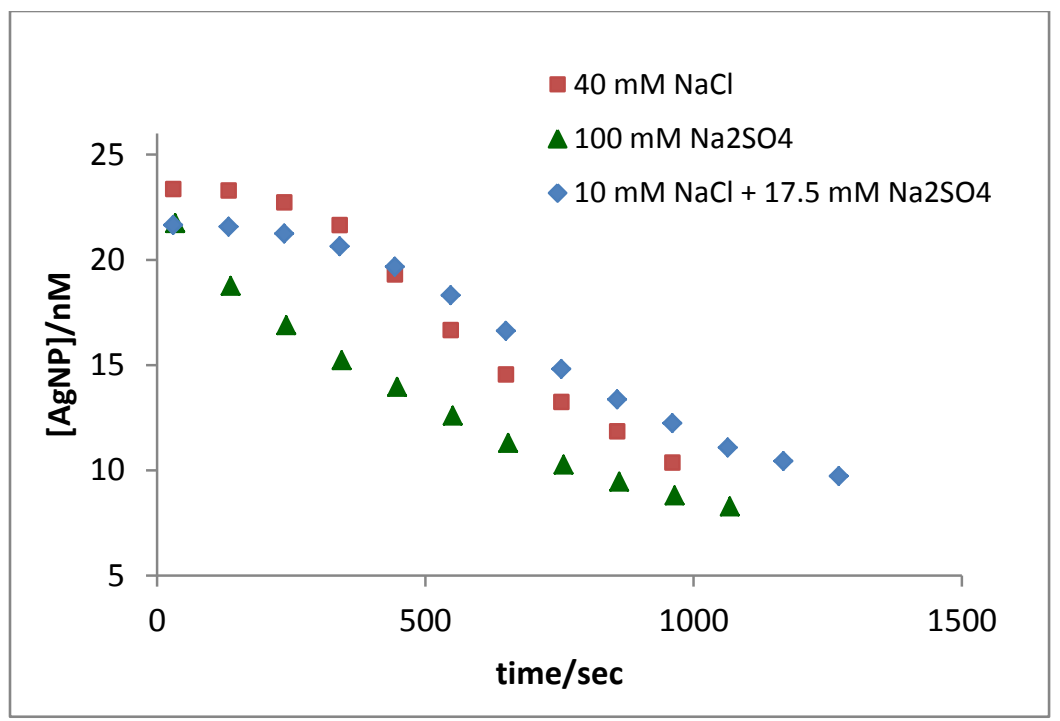

Figure S4. Comparison of the AgNP aggregation rate induced by $40 \mathrm{mM} \mathrm{NaCl}$ (red squares), $100 \mathrm{mM} \mathrm{Na}_{2} \mathrm{SO}_{4}$ (green triangles), or $17.5 \mathrm{mM} \mathrm{Na}_{2} \mathrm{SO}_{4}$ with $10 \mathrm{mM} \mathrm{NaCl}$ added 1 hour prior (blue diamonds). 